\title{
CRIAÇÃO E EXPLORAÇÃO DE UMA INFRA-ESTRUTURA DE INFORMAÇÃO GEOGRÁFICA EM TIMOR-LESTE
}

\author{
João Matos ${ }^{1}$; Miguel Baio ${ }^{1}$; Sara Ribeiro ${ }^{1}$; \\ Carla Gomes ${ }^{1}$; Pedro Trocado ${ }^{1}$
}

\begin{abstract}
Resumo - O projecto de cooperação, apoiado pelo Governo Português e desenvolvido no âmbito da UTL, sob coordenação do grupo GERTiL, envolveu de forma intensa a produção e utilização de informação geográfica. O artigo relata as opções tomadas, que englobam definição de um sistema de coordenadas, a instalação de uma estação de referência GPS, o levantamento de informação no terreno, o uso de imagens de satélite, a incorporação de informação de natureza diversa, e os projectos realizados.

Nos projectos, cuja realização foi possível em virtude da infra-estrutura criada, incluem-se o apoio à elaboração de um plano de desenvolvimento, a «carta escolar», a demarcação das fronteiras e estudos e aplicações de características diversificadas.
\end{abstract}

Palavras-chave : Timor-Leste, planeamento, informação geográfica.

\begin{abstract}
SETTING UP AND EXPLORING GEOGRAPHIC INFORMATION INFRASTRUCTURES IN East Timor. This paper presents a report on the production and usage of Geographic Information applied in a co-operation project with Timor-Leste. The project was funded by the Portuguese Government, developed by technical teams of the Technical University of Lisbon and coordinated by the group GERTiL. The work in the project resorted extensively to geographical information. The article describes the global implementation strategy, namely the definition of a co-ordinate system, the installation of a GPS permanent base-station, field surveys, remote sensing and data gathering.

Different projects made use of the built infrastructure, namely a strategic development plan, the «school mapping» project, the border demarcation and other smaller projects.
\end{abstract}

Key words : East Timor, planning, geographic information.

Resumé - Creation et utilisation d'une infrastructure d'information geograPHIQue a Timor-Leste. Le projet de coopération financé par le Gouvernement portugais et réalisé par l'Université Technique de Lisbonne, dans le cadre du groupe GERTiL, s'est développé en ayant recours à la production et à l'utilisation d'information géographique. On relate les options techniques qui ont été prises, notamment la définition

1 ICIST, Instituto de Engenharia de Estruturas, Território e Construção do Instituto Superior Técnico. http://websig.civil.ist.utl.pt/nucleo7 
d'un système de coordonnées, la mise en place d'une station permanente GPS, le lever d'informations sur le terrain, l'usage d'images de satellite et la combinaison d'informations géographiques aux caractéristiques diversifiées.

Parmi les projets qui ont bénéficié de l'infrastructure créée, on peut citer en particulier le projet de «carte scolaire» et la démarcation de la frontière.

Mots-clés : Timor-Leste, aménagement, information géographique.

\section{INTRODUÇÃO}

A cooperação com Timor-Leste tem mobilizado em Portugal um esforço assinalável em recursos humanos e materiais, reflectindo a solidariedade entre o povo português e o povo timorense numa prioridade nacional. Depois dos incidentes de 1999, a situação do território de Timor-Leste era de carência absoluta em múltiplas áreas, tendo sido mobilizada a ajuda internacional para satisfação das necessidades mais prementes, cobrindo, entre outras, as áreas da segurança, habitação, saúde e educação. Em paralelo, foram sendo construídas as estruturas de administração do território numa perspectiva de desenvolvimento a mais longo prazo e de criação de condições para a formalização da independência, que viria a ocorrer em Maio de 2002.

Com inúmeras iniciativas em curso, os responsáveis timorenses cedo identificaram a necessidade de um trabalho de planeamento que apontasse possíveis estratégias de desenvolvimento e que pudesse apoiar uma aplicação coordenada dos recursos disponíveis. O Governo Português, no âmbito da cooperação bilateral através do Comissariado para o Apoio à Transição em Timor-Leste (CATTL), correspondeu a esse pedido e viabilizou um projecto de apoio a Timor-Leste, no âmbito do planeamento do território, desenvolvido na Universidade Técnica de Lisboa e coordenado por um grupo da Faculdade de Arquitectura (GERTiL - Grupo de Estudos para a Reconstrução de Timor-Leste).

\section{PRINCÍPIOS ORIENTADORES}

A componente de informação geográfica no projecto do GERTiL apresenta uma série de características que a tornam interessante, como um trabalho abrangente e completo. O resultado alcançado derivou de opções estratégicas e técnicas para o desenvolvimento do projecto, da capacidade de produção mobilizada, e o domínio de uma considerável diversidade de áreas de especialização.

O que é actualmente o resultado do projecto, na componente de informação geográfica, resulta de duas opções estratégicas fundamentais. Uma primeira opção, ao nível da coordenação geral, foi a de atribuir grande importância à componente de Sistemas de Informação Geográfica (SIG) no desenvolvimento do projecto, prevendo logo à partida uma adequada afectação de recursos humanos e materiais a esta área. Esta opção traduz o reconhecimento de que a disponibilidade de informação geográfica oferece uma qualidade superior ao trabalho, sustentando as opções de forma mais objectiva e dando ao técnico de planeamento uma base de conhecimento mais completa para o desenvolvimento da sua análise.

Uma segunda opção, ao nível da coordenação da equipa de SIG, foi a de não restringir o trabalho ao exclusivo serviço do projecto, mas realinhar os esforços para o apoio a uma infra-estrutura nacional de informação geográfica em Timor-Leste. Esta opção implicou a realização de um volume de trabalho superior ao previsto e o investimento em infra-estruturas, como a estação GPS de referência, e a tomada de opções, 
como a definição de um sistema de coordenadas, que não são comuns no apoio a trabalhos de planeamento.

A preparação do Sistema de Informação Geográfica foi realizada de acordo com os seguintes princípios:

- privilegiar a cobertura completa do território para cada um dos temas, em conformidade com a abrangência nacional do trabalho de planeamento;

- constituir uma base consistente para todos os temas, ou seja, garantir que todos os temas partilhem as mesmas fronteiras e sejam sobreponíveis com exactidão;

- aplicar padrões de qualidade compatíveis com os objectivos específicos do projecto e com a futura utilização dos dados numa eventual futura infra-estrutura geográfica nacional de Timor Leste.

O trabalho que, numa fase inicial, consistiu na conversão da cartografia existente para suporte digital e subsequentes operações de integração em SIG, acolheu os contributos do Instituto Geográfico do Exército, do Instituto Português de Cartografia e Cadastro e do Instituto de Investigação Científica e Tropical.

\section{DESENVOLVIMENTO DOS TRABALHOS BÁSICOS}

\section{Sistema de Coordenadas e Apoio Geodésico}

Atendendo a que a informação geográfica disponível, de proveniência diversa, se encontrava em diferentes sistemas de coordenadas, foi adoptado um sistema de coordenadas próprio, seguindo a tendência internacional neste domínio e adequado à actual vulgarização da utilização de GPS para posicionamento. O sistema de coordenadas é definido pelas seguintes características:

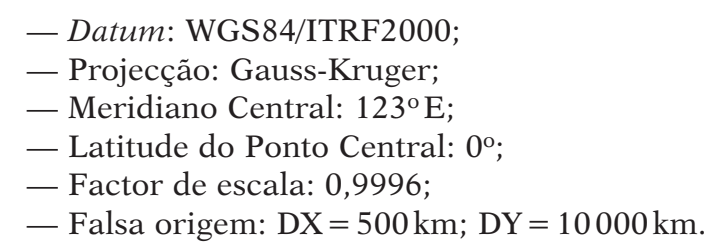

Este sistema corresponde ao Fuso 51 do sistema internacional UTM, estendido à totalidade do território. A aplicação estrita das convenções UTM obrigaria a dividir o território pelos Fusos 51 e 52, impedindo a sua representação simultânea em coordenadas cartográficas.

A opção pelo Datum WGS84, já em uso na anterior cartografia $1 / 25000$, é adequada à utilização de posicionamento com receptores GPS, dispensando as operações de transformação de coordenadas, necessárias nas situações em que se utiliza um datum diferente.

A transformação de coordenadas da cartografia portuguesa anterior a 1975 foi feita com pontos de controlo distribuídos homogeneamente pelo território, identificáveis na cartografia $1 / 25000$ do período de administração indonésia e na cartografia $1 / 50000$ portuguesa.

Para a realização de trabalhos de posicionamento, e na ausência de informação sobre a rede geodésica indonésia, foi instalada uma mínima infra-estrutura geodésica com uma estação GPS de referência em Díli e alguns vértices de apoio materializados noutros pontos do território. Foi instalada uma estação de referência Leica RS530, de 
dupla frequência, adequada a trabalhos de elevada precisão e dotada em simultâneo da capacidade de emissão de sinal para correcção diferencial em tempo real.

Este equipamento permitiu a ligação à rede mundial de estações de referência IGS (International GPS Service), constituindo assim uma ligação de elevada exactidão posicional ao Datum WGS84. As coordenadas obtidas são apresentadas no Quadro 1.

Quadro 1 - Coordenadas da estação de referência em Díli.

Table 1 -Co-ordinates of the reference station in Dili.

\begin{tabular}{lcc}
\hline \multicolumn{1}{c}{ Geodésicas WGS84 } & \multicolumn{1}{c}{ Geocêntricas } & UTM51 \\
\hline$\varphi=8^{\circ} 33^{\prime} 14.0497 » \mathrm{~S}$ & $\mathrm{X}=-3670054.906 \mathrm{~m}$ & $\mathrm{E}=783983.039 \mathrm{~m}$ \\
$\lambda=125^{\circ} 34^{\prime} 47.14118 \mathrm{E}$ & $\mathrm{Y}=5130105.943 \mathrm{~m}$ & $\mathrm{~N}=9053515.103 \mathrm{~m}$ \\
$\mathrm{~h}=61.313 \mathrm{~m}$ & $\mathrm{Z}=-942410.833 \mathrm{~m}$ & $\mathrm{H}=14.492$ \\
\hline
\end{tabular}

As coordenadas foram calculadas a partir das estações IGS australianas de Karratha e Yaragadee, após vários ensaios com outras estações IGS situadas na região de Timor. As coordenadas estão afectadas de um erro estimado em aproximadamente $4 \mathrm{~cm}$, tanto em planimetria como em altitude.

\section{Conversão e produção de informação}

Grande parte do trabalho consistiu na compilação e integração de informação geográfica já existente. A base mais actual e completa disponível era a série cartográfica 1/25000 indonésia (elaborada pelo BAKOSURTANAL). Procedeu-se à vectorização das folhas desta série cartográfica, tendo no entanto sido necessária a sua correcção geométrica (ver 3.), por forma a que a sua informação pudesse ser utilizada como estruturante.

Num projecto desta natureza, agregar de forma consistente informação de natureza tão diversificada obriga a um volumoso trabalho de edição que garanta, por exemplo, que os corpos de água na carta de solos sejam os mesmos da cartografia 1/25000, que os limites administrativos sejam coincidentes e que a linha de costa seja a mesma em todos os conjuntos de dados geográficos. Um exemplo das edições realizadas é ilustrado na fig. 1, sendo apresentada a imagem original da Carta de Solos, geo-referenciada com pontos de controlo da cartografia 1/25000, e a versão vectorial final obtida após duas transformações geométricas e uma edição de compatibilização.

A produção directa de informação baseou-se nas imagens LANDSAT 7, na imagem Ikonos de Díli e em levantamentos realizados com GPS na rede rodoviária e no posicionamento de equipamentos públicos. É ainda de realçar que foi necessário refazer toda a delimitação administrativa, compilando informação indonésia, informação proveniente de vários departamentos da administração de Timor-Leste e ainda de reconhecimento no terreno. A melhor versão disponível de limites administrativos resultou deste projecto, sendo posteriormente distribuída com pequenas alterações pelo Ministério da Agricultura de Timor-Leste.

Já o trabalho de delimitação da fronteira entre Timor-Leste e Indonésia baseia-se unicamente em informação produzida directamente, a partir de levantamento no terreno com GPS e imagens Ikonos pan-sharpened. 


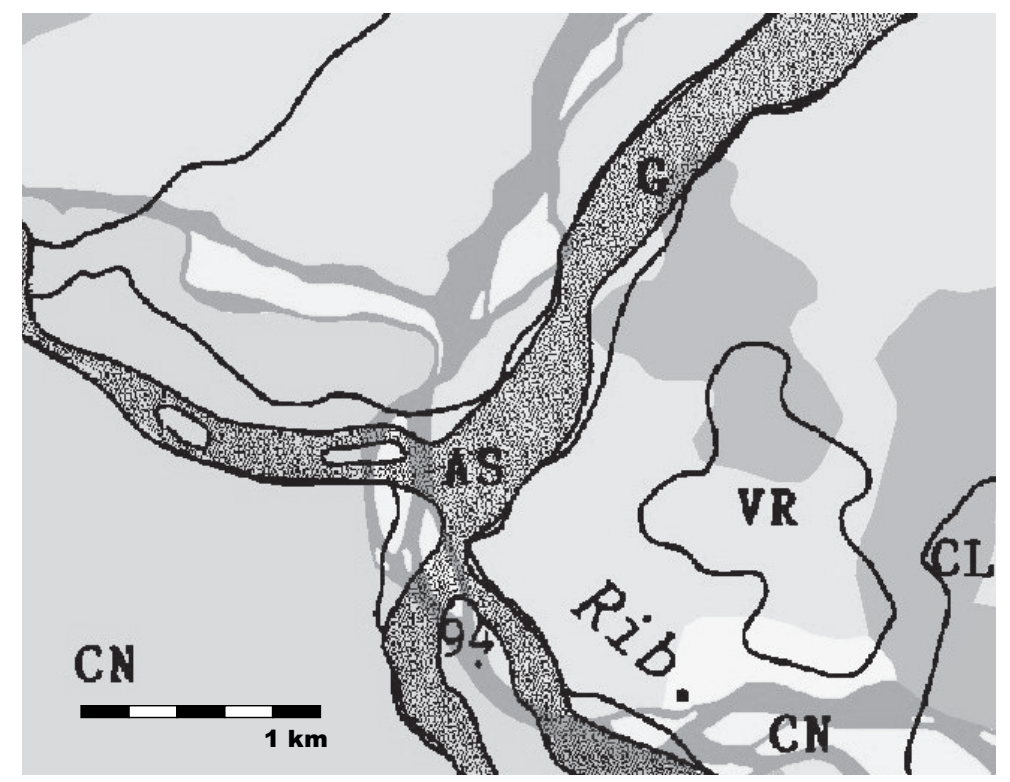

Fig. 1 - Ilustração da correcção geométrica e edição feita à Carta de Solos.

Fig. 1 - Illustration of Geometric Correction made to soil map.

Além da operação com a informação, foram produzidos diversos mapas impressos e com distribuição pública, nomeadamente os Mapas de Timor nas escalas 1/250000, produzido para o Ministério da Educação, Cultura e Desporto e distribuído nas escolas de Timor-Leste, e o Mapa de Timor à escala 1/500 000, com distribuição ao público.

O Quadro 2 sintetiza os principais conjuntos de dados geográficos e produtos associados ao projecto.

\section{Análise da exactidão posicional e procedimentos de compatibilização}

Antevendo a necessidade de levantamento de informação no terreno e a compatibilização de informação de diversas fontes, tornou-se evidente a necessidade de proceder à avaliação da exactidão posicional da base cartográfica à escala 1/25000.

Com vista à avaliação da exactidão posicional foram determinadas posições com GPS, adoptando-se o posicionamento com correcção diferencial, distribuídas pelo território. O resultado revelou discrepâncias acima de qualquer limite de tolerância (figura 2), face a futuros trabalhos de levantamento com GPS e à aplicação de operações de análise espacial. A correcção geométrica simultânea para todo o território (figura 3), aplicando uma transformação afim (MAтоs, 1998), não produziu no entanto um resultado satisfatório. Optou-se então por realizar essa mesma transformação seccionando a informação por distrito, obtendo-se finalmente um resultado que, não sendo bom, era já difícil de melhorar (figura 4), subsistindo um erro médio de $18 \mathrm{~m}$. Esta solução obrigou a editar todos os Conjuntos de Dados Geográficos entretanto produzidos, uma vez que se tinha assumido o risco de iniciar a produção antes de a análise da exactidão posicional estar completa, permitindo que as equipas de planeamento iniciassem o seu trabalho dispondo de informação que caracterizasse o território. 
Quadro 2 - Conjuntos de dados geográficos e produtos.

Table 2 - Geographical datasets and products.

\begin{tabular}{l|l}
\hline Administrativos e Socio-Económicos & Recursos Naturais \\
Limites Administrativos & Carta Geológica \\
\multicolumn{1}{c|}{ Sucos } & Ocupação de Solo \\
\multicolumn{1}{c|}{ Distritos } & Regiões Cafeícolas de Timor \\
Carta de Solos & Recursos Naturais \\
População & Caracterização Ambiental \\
Densidade populacional & Esboço Climatológico \\
Mapa Linguístico & Temperatura \\
Índice de Desenvolvimento do Suco & Precipitação \\
Cultura Principal por Suco & Bacias Hidrográficas \\
Tempo de acesso à Capital de Distrito & Fisiografia \\
Infra-estruturas e Equipamentos & Declives \\
Saúde & Orientação de Encostas \\
Segurança & Estudos \\
Electricidade & Risco da Malária \\
Portos e Aeroportos & Análise do Erro Posicional da Cartografia \\
Escolas & Cobertura para Telecomunicações \\
Antenas de telecomunicações & Risco de inundação \\
Abastecimento de água & Planeamento da rede viária de Timor Leste \\
Informação de base & Mapas e outros produtos \\
Espaço Urbano & Planta de Díli \\
Rede Viária & Mapa de Timor-Leste (1/250 000) \\
Hidrografia & Mapa de Timor-Leste (1/750 000) \\
Toponímia & Cartografia de Apoio às Eleições \\
Modelo digital de terreno & Atlas de Timor Leste \\
Cartografia $1 / 25000$ (imagem) & Imagens de Satélite \\
Cartografia 1/50000 (imagem) & LANDSAT (Timor-Leste) \\
Cartografia 1/250 000 (imagem) & IKONOS (Díli e Fronteira) \\
Cartografia 1/500 000 (imagem) &
\end{tabular}

\section{CASOS DE UTILIZAÇÃO DA INFORMAÇÃO GEOGRÁFICA}

\section{O Plano Estratégico para Timor-Leste (PETiL)}

A elaboração de um Plano Estratégico para Timor-Leste foi a primeira tarefa a realizar no âmbito do projecto GERTiL, envolvendo várias equipas da UTL, sendo o IST responsável pela componente de Informação Geográfica (Núcleo 7 - ICIST), que prestou apoio às restantes equipas, pertencentes à Faculdade de Arquitectura, ao Instituto Superior de Agronomia, ao Instituto Superior de Economia e Gestão, ao Instituto Superior de Ciências Sociais e Políticas, ao Instituto Superior Técnico e à Faculdade de Medicina Veterinária.

As equipas das áreas sectoriais desenvolveram o seu trabalho nas respectivas áreas temáticas, do qual resultou o Plano Estratégico para Timor-Leste (PETiL), apresentado publicamente em Díli (Julho de 2001). 


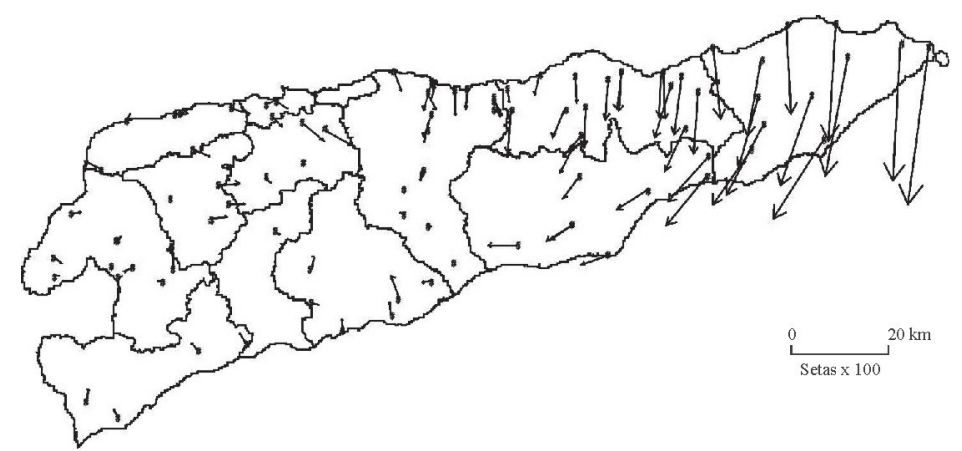

Fig. 2 - Vectores de erro posicional absoluto da base cartográfica 1/25000 (máximo $=460 \mathrm{~m}$, média $=87 \mathrm{~m})$.

Fig. 2 - Absolute positional error vectors of the 1/25000 base map ( máximo $=460 \mathrm{~m}$, média $=87 \mathrm{~m}$ ).

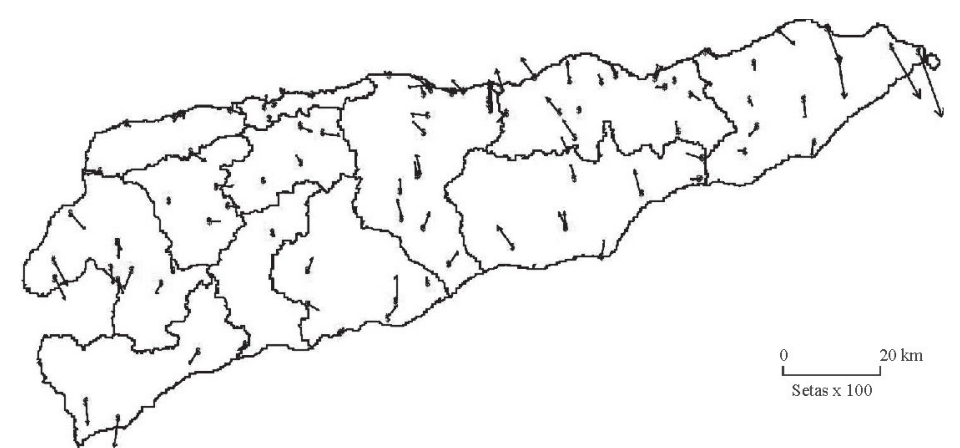

Fig. 3 - Vectores de erro posicional absoluto após transformação linear aplicada a todo o território (máximo $=210 \mathrm{~m}$, média $=44 \mathrm{~m}$ ).

Fig. 3 - Absolute positional error vectors after linear transformation applied to the whole territory ( aximum $=210 \mathrm{~m}$, average $=44 \mathrm{~m}$ ).

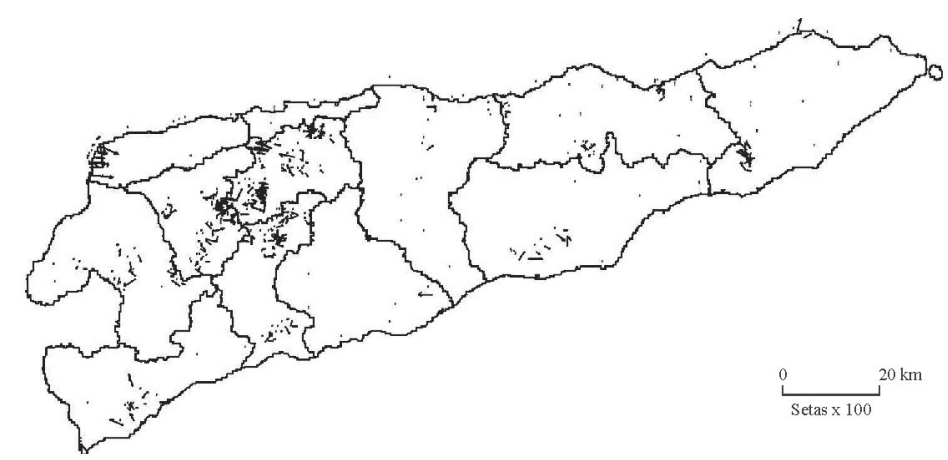

Fig. 4 - Vectores de erro posicional absoluto após transformação linear aplicada por distrito (máximo $=59 \mathrm{~m}$, média $=18 \mathrm{~m}$ ).

Fig. 4 -Absolute positional error vectors after linear transformation applied to by district ( maximum $=59 \mathrm{~m}$, average $=18 \mathrm{~m}$ ). 
Ao nível de planeamento estratégico, a informação geográfica foi predominantemente utilizada como elemento de consulta e de suporte a propostas. As equipas dispuseram desde cedo, no calendário do projecto, de informação geo-referenciada relativa a dados socio-económicos, equipamentos, rede viária, orografia e clima, entre outros. Em alguns domínios, além da simples compilação, foi necessário operar sobre essa informação, nomeadamente para o estudo do potencial agrícola, do potencial em energias alternativas, das acessibilidades e da viabilidade para uma rede de telecomunicaçóes.

\section{O projecto da Carta Escolar}

\subsection{Descrição Geral}

O trabalho desenvolvido no âmbito do PETiL teve como consequência o pedido, por parte do Departamento de Educação da ETTA (East Timor Transitory Administration), de um plano para os equipamentos de ensino (School Mapping), coordenado pelo CESUR, em parceria com o ICIST e o GERTiL. Este projecto teve a duração de seis meses e terminou no final de Setembro de 2001, beneficiando da infra-estrutura de informação geográfica e de logística entretanto instalada, num estudo com dimensão sem paralelo, mesmo em território português.

O trabalho de elaboração da Carta Escolar teve uma componente de informação geográfica com intervenção ao nível de:

— preparação da informação de base (rede viária, limites administrativos, declives, aglomerados urbanos, etc.);

- posicionamento das escolas com GPS;

— análise espacial para apoio à definição das áreas de influência das escolas;

- desenho de territórios educativos.

— apresentação de resultados.

\subsection{Preparação da Informação de Base}

A informação de base utilizada proveio na sua maior parte do trabalho de compilação e edição de informação geográfica produzido no âmbito do projecto GERTiL. No decurso do projecto da Carta Escolar foram feitos melhoramentos nos temas da rede viária, da toponímia e dos limites administrativos.

Relativamente à toponímia, a deslocação às escolas evidenciou casos frequentes de topónimos existentes na cartografia, tanto portuguesa como indonésia, não identificados pelos habitantes e os topónimos indicados pelos habitantes que não constavam de nenhuma cartografia conhecida.

Os limites administrativos apresentaram grandes dificuldades, atendendo a que a informação estatística disponível estava referenciada a uma organização hierárquica (Distrito; Sub-distrito; Suco; Aldeia) que não tinha geo-referenciação. Foram disponibilizados limites administrativos esquemáticos pelo Departamento de Agricultura da ETTA, que foram adaptados tendo em conta o relevo, a hidrografia, limites administrativos mais antigos e o testemunho directo dos habitantes nas escolas visitadas. A informação de limites administrativos é actualmente a melhor possível, não devendo no entanto ser considerada como tendo carácter oficial, uma vez que resultou unicamente da necessidade de referenciar com a melhor qualidade possível os dados estatísticos. 


\section{Posicionamento das Escolas com GPS}

Para cada escola foi feito o posicionamento com GPS, operado para correcção diferencial pós-processada a partir da estação de referência de Díli. Foram utilizados quatro receptores Leica GS50 e, com utilização mais reduzida, um receptor Trimble GEO-Explorer II. Para cada escola foram determinados pontos para portão de entrada, centro geométrico e, na quase totalidade dos casos, foi possível levantar o contorno do terreno afecto à escola.

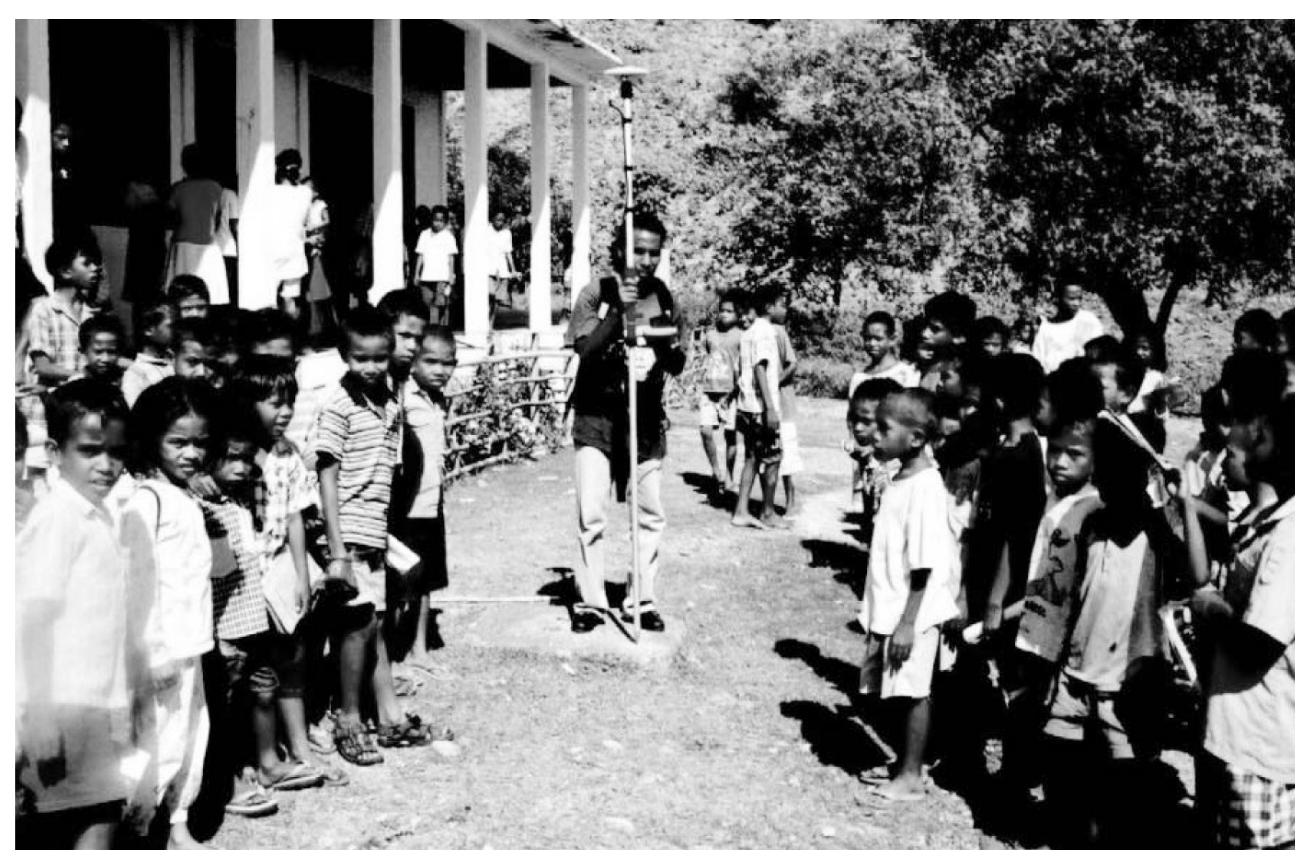

Fig. 5 - Estacionamento com receptor GPS.

Fig. 5 - Survey with GPS.

A quase totalidade das escolas foi posicionada com erro absoluto inferior a $1 \mathrm{~m}$. Esta exactidão posicional, superior ao estritamente necessário para o posicionamento pontual da escola (fig. 5), foi no entanto necessária para o levantamento das áreas no terreno envolvente (a técnica de posicionamento imediatamente inferior, em termos de exactidão posicional, encontra-se bastante distante, com erros da ordem de 10 a 30m).

O posicionamento foi realizado em pontos conspícuos, tendo sido deixadas marcas metálicas em muitas das escolas, materializando os pontos que foram coordenados. A figura 6 ilustra, com sobreposição em imagem de satélite de alta resolução, um exemplo do trabalho de posicionamento realizado. 


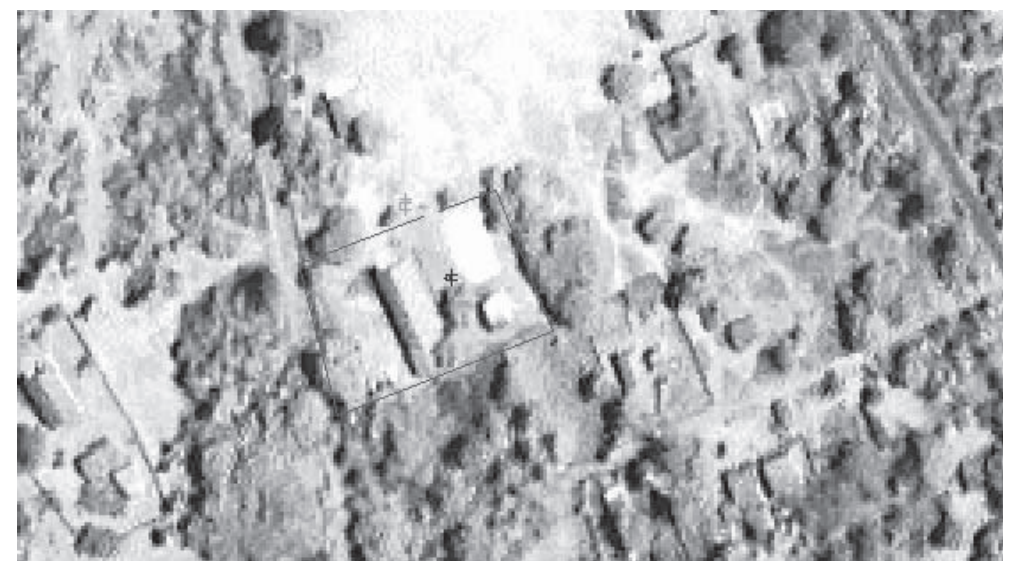

Fig. 6-Exemploilustrativo de levantamento de escola, apresentado sobre imagem IKONOS. Fig. 6 - Illustration of school survey, depicted over IKONOS image.

\section{Análise Espacial}

A determinação da acessibilidade às escolas foi feita com uma superfície de custo (velocidade de deslocação a pé), construída considerando a velocidade de deslocação, o desenvolvimento do percurso em estrada ou fora de estrada, o declive, os obstáculos em zonas urbanas, os obstáculos naturais e a vegetação (fora de estrada). A figura 7 ilustra o resultado da determinação de zonas acessíveis em menos de 45 minutos e em menos de 10 minutos, centradas na escola de Sabuli.

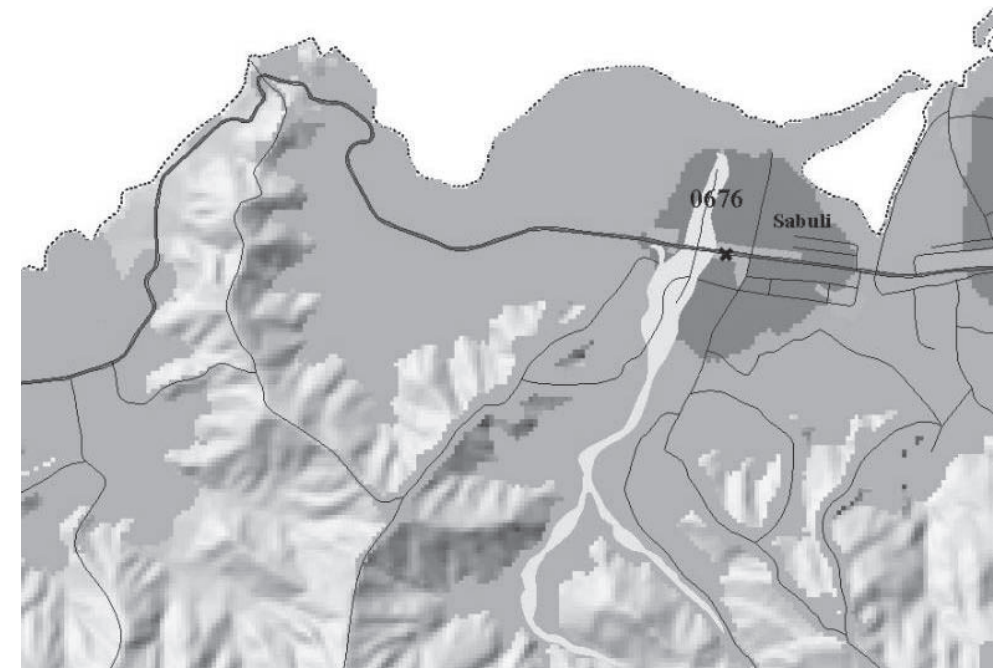

Fig. 7 - Ilustração de zonas de acessibilidade para a escola de Sabuli (ver texto).

Fig. 7 - Illustration of accessibility areas for the Sabuli school (see text). 
As áreas de influência foram construídas sobre a superfície de tempo de percurso. Os territórios educativos foram desenhados tendo em consideração as áreas de influência, os limites administrativos, a população escolar que irão conter e a disponibilidade de escolas com tipologia existente ou proposta adequadas.

A contabilização da população foi feita considerando a informação ao suco e ao sub-distrito, para os casos em que os territórios educativos seguiam as fronteiras administrativas. Nalguns casos especiais foi feita uma distribuição da população em contínuo, por desagregação dos valores de população (agregados às unidades administrativas) pelas áreas urbanas, proximidade de estradas e declive baixo.

\section{A demarcação da fronteira}

O trabalho de demarcação da fronteira entre Timor-Leste e a Indonésia iniciou-se ainda com o território sob a administração da UNTAET e prosseguiu já com o Governo de Timor-Leste. Foi decidido por ambos os países a adopção da fronteira acordada entre Portugal e Holanda, estabelecida com um tratado em 1904 e uma decisão arbitral, para o enclave de Oecussi, em 1915. O trabalho presente consiste na interpretação do tratado e elaboração de uma caracterização e materialização actuais para a fronteira.

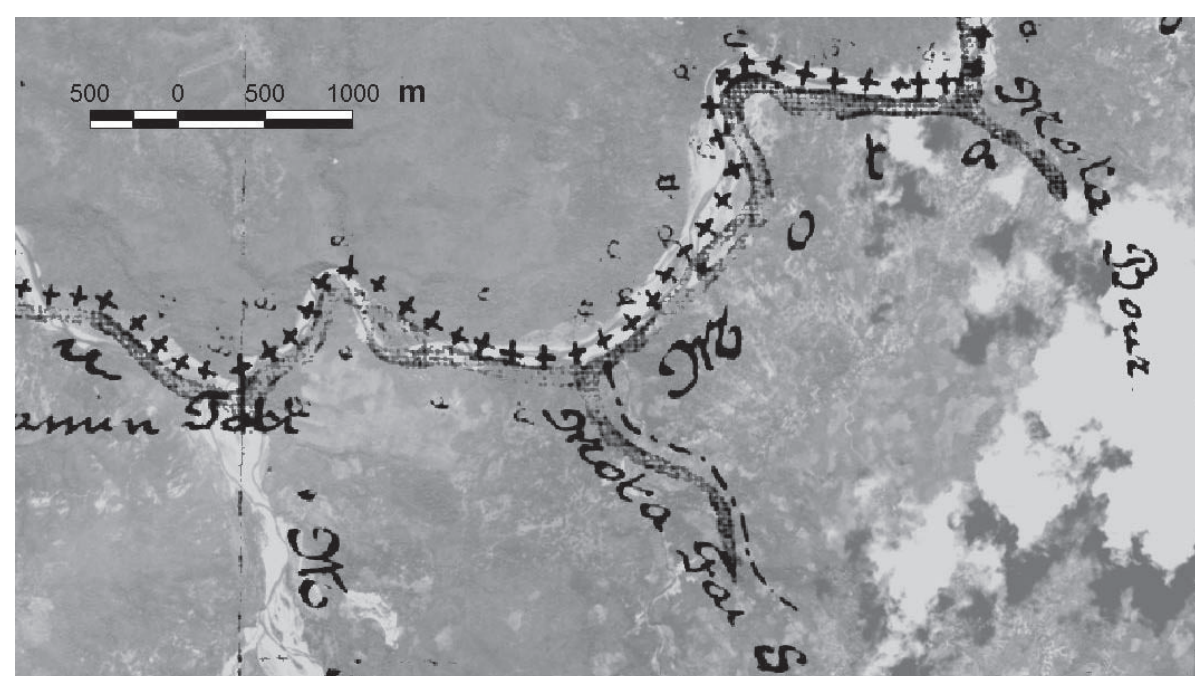

Fig. 8 - Sobreposição da fronteira de 1904 (1:100000) com a imagem de satélite de alta resolução IKONOS.

Fig. 8-Overlay of the 1904 borderline (1:100000) with IKONOS high resolution satellite image.

Na abordagem inicial ao problema, foi utilizada a informação geográfica já preparada, à qual se sobrepôs a cartografia dos tratados (fig. 8) realizados no início do século, procurando ainda identificar-se a toponímia referida nestes documentos.

Posteriormente foi adquirida uma cobertura completa da fronteira em imagens IKONOS, que serve agora de base aos trabalhos cartográficos de delimitação. 


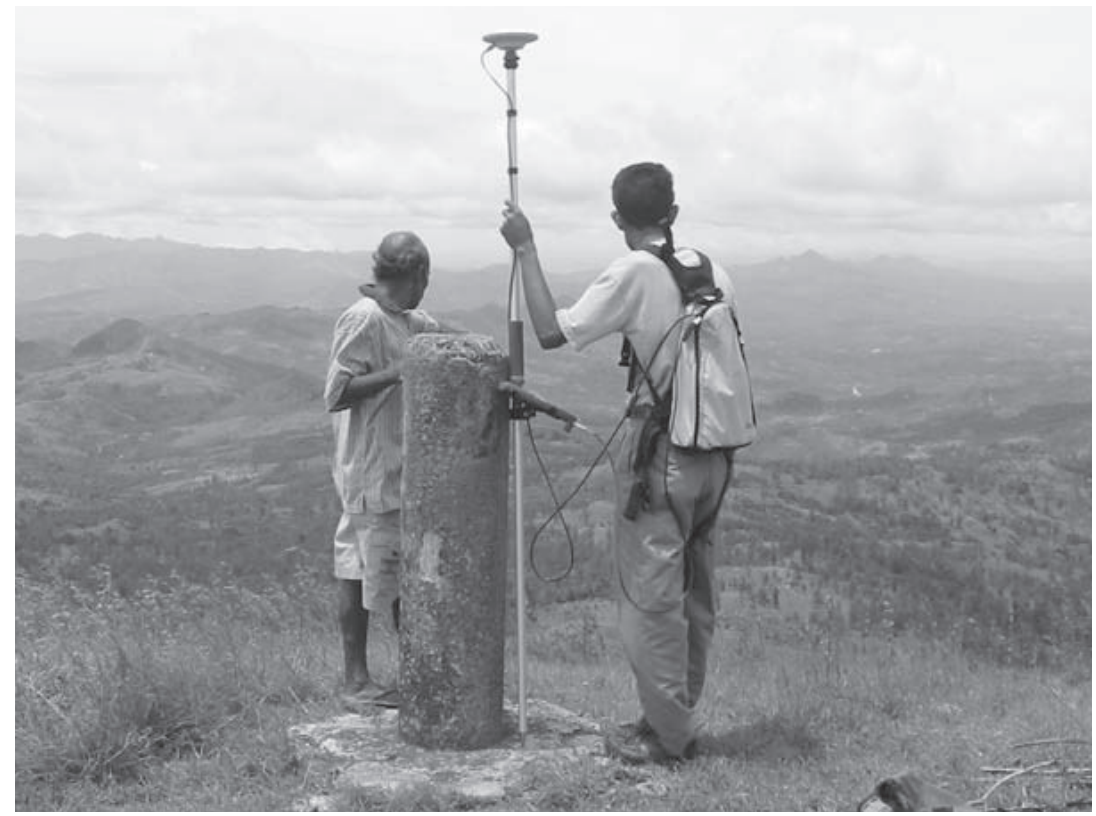

Fig. 9 - Marco antigo encontrado no cume do Bijael-Sunan (Oecussi).

Fig. 9 - Old marker on the summit of Bijael-Sunan (Oecussi).

Um dos problemas no processo de interpretação do tratado é a mudança do curso dos rios utilizados como fronteiras naturais (JonEs,1945). Na figura abaixo é ilustrada a alteração no leito de rios, junto à sua foz, detectada entre 1989 e 1999, com recurso a imagens LANDSAT (a ilustração não diz respeito a rios da fronteira, por razões que se prendem com a natureza do processo de delimitação da fronteira, mas a situações similares).
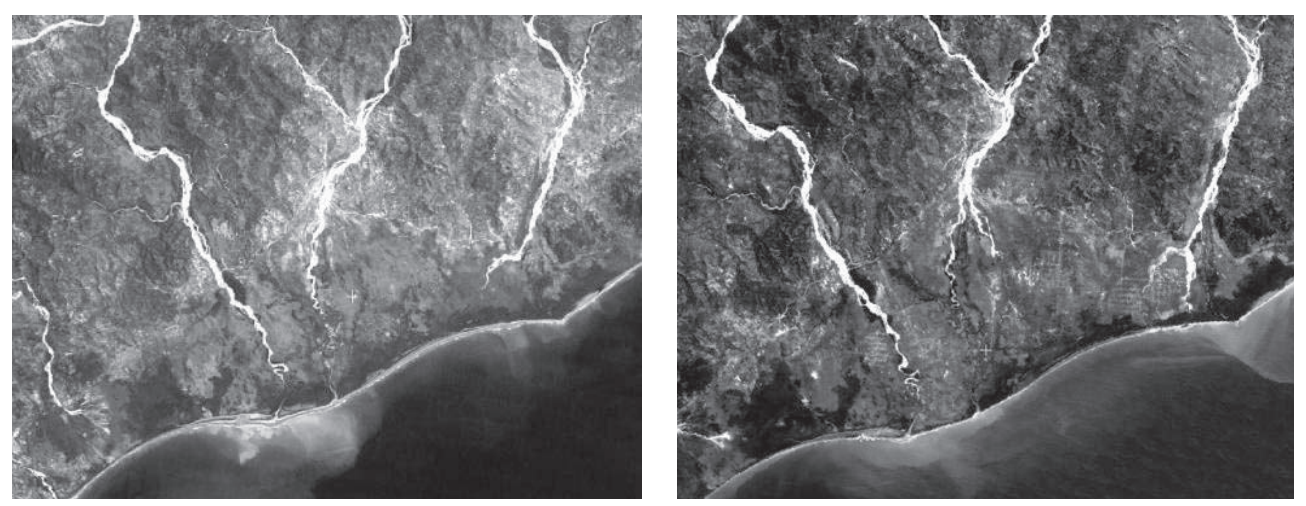

Fig. 10 - Imagens LANDSAT de 1989 e 1999.

Fig. 10 - LANDSAT images of 1989 and 1999. 


\section{Outros resultados da aplicação da informação geográfica}

Existindo informação geográfica diversificada, consistente e organizada surgem naturalmente diversas possibilidades de utilização. A informação geográfica coligida serviu assim de base aos seguintes trabalhos:

- Atlas linguístico de Timor-Leste;

- Elaboração do mapa de Timor-Leste para utilização pelas escolas;

- Elaboração dos mapas de apoio aos observadores internacionais nos processos eleitorais, com indicação dos postos de votação;

- Carta de intervenções policiais em Díli;

- Atlas de Timor-Leste;

- Planta de Díli (feita com base em imagem IKONOS).

Parte da informação foi ainda disponibilizada a instituições civis e militares portuguesas para a realização de trabalhos diversos.

\section{CONSIDERAÇÕES FINAIS}

Para além da importância dos resultados obtidos, o trabalho realizado teve um interesse técnico significativo. Esse interesse reside em primeiro lugar na diversidade de tecnologias e competências requeridas, nomeadamente em:

- Geodesia e Cartografia Matemática: na definição e materialização de um sistema de geo-referenciação;

— conversões entre sistemas de coordenadas: na compatibilização da informação geográfica de diferentes sistemas de referência;

— posicionamento com GPS: na ligação de Timor-Leste à rede mundial IGS e no levantamento de escolas, estradas e outras características geográficas;

- Detecção Remota: no processamento de imagens de satélite LANDSAT e IKONOS;

— operação com Modelos Digitais de Terreno: na realização de inúmeros estudos, entre os quais a localização de antenas de telecomunicações e a delimitação de zonas de risco de cheia;

— operação com Bases de Dados: no tratamento de toda a informação alfanumérica;

- Serviço de Informação Geográfica na Internet: no apoio às várias equipas e na disseminação da informação por utilizadores não especializados;

— análise de qualidade de informação geográfica: na verificação da informação de base e na sua correcção, quando possível;

- modelação geográfica: no entendimento das características geográficas próprias de Timor-Leste e da forma de as modelar em SIG;

- análise espacial: em inúmeras operações, nomeadamente na determinação de áreas de influência para as escolas, na contabilização da população coberta por uma dada configuração de cobertura de antenas de telecomunicações e na determinação de adequação do solo ao uso agrícola;

— desenho cartográfico: na elaboração dos diversos mapas para ilustração de resultados, para distribuição ou simplesmente para orientação no território.

A realização de um trabalho deste tipo envolve dificuldades consideráveis em três vertentes: a logística, a diversidade de áreas de especialização requeridas e a capacidade de produção. Seria suficiente, para o insucesso do projecto, que uma só destas componentes não fosse tratada adequadamente. 


\section{AGRADECIMENTOS}

Os autores gostariam de, em primeiro lugar, manifestar o seu reconhecimento à Prof. Isabel Themido, que coordenou o que veio a ser o seu último projecto com a «Carta Escolar de Timor».

Os trabalhos descritos não teriam sido possíveis sem o apoio de várias instituições, nomeadamente o Governo Português, através do CATTL, o Banco Mundial, a USAID e as Nações Unidas. A estação GPS de referência em Timor-Leste foi instalada com o apoio da Leica Geosystems.

Um trabalho desta natureza é necessariamente um trabalho de equipa. A função de ligação permanente em Timor foi desempenhada por Fernanda Alves, Nelson Silvestre, Gonçalo Gueifão, Ana Amorim e Sara Ribeiro. A lista de colaboradores que, tanto em Portugal como em Timor-Leste, participaram nos trabalhos de demarcação da fronteira e na elaboração da carta escolar é demasiado extensa para ser aqui apresentada mas os autores deixam expresso o seu reconhecimento a todos eles.

\section{BIBLIOGRAFIA}

Jones, S. (1945) - Boundary-Making. Carnegie Endowment for International Peace, Washington.

Matos, J. e Gonçalves, A. (1998) - Measurement and Analysis of Positional Error. Proceedings of Spatial Data Handling 98. Vancouver. 